\title{
Urban farming in Hong Kong
}

\author{
Daniel Wai-tin Chan \\ From Practical Social and Industrial Research (PSIR) Symposium 2015 \\ Wan Chai, Hong Kong. 27 November 2015
}

\section{Background}

Suitable indoor green plants have been tested and shown to reduce Volatile Organic Compounds by $80 \%$ and carbon dioxide by up to $25 \%$ in singe offices, offering significant health benefits to office workers $[1,2]$.

Further studies have also shown that a leafy office relieves stress and reduces negative mood states by up to $60 \%$ and just one plant is enough to make a positive difference in the workplace. This research has shown that plants in an office environment can result in $37 \%$ reduction in tension/anxiety, a $58 \%$ reduction in depression/dejection, a $44 \%$ reduction in anger/hostility, a $38 \%$ reduction in fatigue, a $30 \%$ reduction in confusion and a $5 \%$ increase in vigour [3-6].

Other researchers advocate growing green vegetables indoor which grow faster in higher carbon dioxide concentration indoor, and faster than outside in winter since the indoor space in warm. Green vegetables turn carbon dioxide into food eaten by people in the food chain, i.e. as fuel and food for humans, contributing significantly to absorbing carbon dioxide than growing non-food green plants which soon will mostly decay and turn into atmospheric carbon dioxide again $[7,8]$.

\section{Results}

This paper attempts to integrate all the above benefits of growing indoor green plants together by proposing an illustrative selection of a variety of green plants which will demonstrate collectively the above benefits inside an office.

Furthermore the more carbon dioxide, which is emitted by humans indoor, absorbed into indoor green plants, which also enhance indoor air quality, the more energy is saved in heating up or cooling down outside air which is needed traditionally to dilute indoor air, by exhausting the same amount to maintain an acceptable level of indoor air

Correspondence: daniel-chan@vtc.edu.hk

Faculty of Science and Technology, Technological and Higher Education Institute of Hong Kong, Hong Kong

\section{SpringerOpen ${ }^{\circ}$}

quality, because the outdoor air intake will be much reduced. This will offer extra benefits to cities such as Beijing which is suffering from dust storms, demanding expensive and energy in filtering outside air for intake into buildings.

\section{Conclusions}

The overall benefits as discussed will expectedly bring a new paradigm in interior space utilization in greening and growing vegetables and other green plants in the built environment. This will also contribute to combating climate change.

Published: 27 November 2015

\section{References}

1. Ambius Fact Sheet: Plant life balance [Internet]. - [cited 2015 May 29]. [http://www.ambiusindoorplants.com.au/news/latest-news/AMB468\%20\% 20Fact\%20Sheet\%20PLB\%209-5.pdf], Available from.

2. Plant for People. Plant for people [Internet]. - [cited 2015 May 29]. [http://www.plants-for-people.org/eng/], Available from.

3. Wood RA, Burchett MD, Alquezar A, Orwell R, Tarran J, Torpy F: The pottedplant microcosm substantially reduces indoor air VOC pollution: I. Office field-study. Water, Air, and Soil Pollution 2006, 175(1):163-180.

4. Orwell R, Wood R, Burchett M, Tarran J, Torpy F: The potted-plant microcosm substantially reduces indoor air VOC pollution: II. Laboratory study. Water, Air, and Soil Pollution 2006, 177(1):59-80.

5. Tarran J, Torpy F and Burchett M: Use of living pot-plants to cleanse indoor air - research review. Proceedings of 6th Internat Conf on Indoor Air Quality, Ventilation \& Energy Conservation- Sustainable Built Environment Sendai, Japan; 2007, October 28-31; 2007.

6. Burchett M, Torpy F, Brennan J, Craig A: Greening the Great Indoors for Human Health and Wellbeing. Sydney: Plants and Indoor Environmental Quality Group, Centre for Environmental Sustainability (CEnS) University of Technology Sydney; 2010.

7. Briz J, Cheung KP, Chan DWT, et al: Chapter 18: Challenges to improve green urban environment by urban agriculture: The case of Hong Kong and Madrid. Green cities in the world. Madrid: World Green Infrastructure Network \& Editorial Agricola Española S.A; 2015, 311-330.

8. Cheung KP, et al: Innovative Urban Roof Greenhouses enriched with carbon dioxide breathed out by human beings [Internet] c2014 - [cited 2015 May 29] [http://icee.hku.hk/chinachem01.pdf], Available from.

doi:10.1186/2193-1801-4-S2-P9

Cite this article as: Chan: Urban farming in Hong Kong. SpringerPlus 2015 4(Suppl 2):P9. 